\title{
UMA POSSIBILIDADE DE PESQUISA EM HISTÓRIA DA ARTE EM UM MUSEU: A EXPERIÊNCIA DA EXPOSIÇÃO "ALMEIDA JÚNIOR: UM CRIADOR DE IMAGINÁRIOS" NA PINACOTECA DO ESTADO DE SÃO PAULO
}

\author{
Ana Paula Nascimento \\ Doutoranda da Faculdade de Arquitetura e Urbanismo da Universidade de \\ São Paulo \\ Pesquisadora da Pinacoteca do Estado de São Paulo
}

\section{Introdução}

Este trabalho busca apresentar resumidamente os caminhos e escolhas de pesquisa para a exposição "Almeida Júnior: um criador de imaginários", realizada na Pinacoteca do Estado de São Paulo entre 25 de janeiro e 15 de abril do corrente ano. Minha atuação como curadora assistente dessa mostra $^{1}$ e como pesquisadora do museu acima mencionado, possibilitou um trabalho de envergadura diferenciada dentro de uma instituição museal especialmente numa era comumente chamada a do espetáculo midiático, em que muitas têm como principal objetivo a apresentação de megaexposições, normalmente concebidas por terceiros -, e procurou aliar uma ampla pesquisa, cuja materialização se deu pela organização espacial da exibição, que evidenciou escolhas curatoriais; pelos produtos gerados e pelas atividades desenvolvidas junto ao público, colocando em destaque a produção desse artista para além das obras já consagradas.

\section{A Pinacoteca do Estado e a produção de José Ferraz de Almeida Júnior}

José Ferraz de Almeida Júnior (Itu, São Paulo, 1850 - Piracicaba, São Paulo, 1899) é considerado por muitos historiadores de diferentes períodos o mais importante pintor paulista da segunda metade do século XIX, especialmente pela inclusão de telas com temática regionalista.

\footnotetext{
${ }^{1} \mathrm{O}$ trabalho foi realizado em parceria com a curadora-geral da exposição, a Prof. ${ }^{a}$ Dr. ${ }^{a}$ Maria Cecília França Lourenço que, dentre os importantes estudos e linhas de pesquisas realizadas, é grande estudiosa da obra de José Ferraz de Almeida Júnior.
} 
É importante ressaltar que a Pinacoteca do Estado de São Paulo é o museu de arte mais antigo da cidade de São Paulo. Inaugurada em 1905 como uma espécie de extensão do Liceu de Artes e Ofícios ${ }^{2}$ - ocupando uma das salas desse estabelecimento de ensino -, a Pinacoteca possui, desde sua fundação, obras do pintor ituano. Atualmente, a instituição é guardiã de significativa parcela da produção de Almeida Júnior, formando um diferenciado e importante conjunto monográfico oitocentista preservado de um artista em museu.

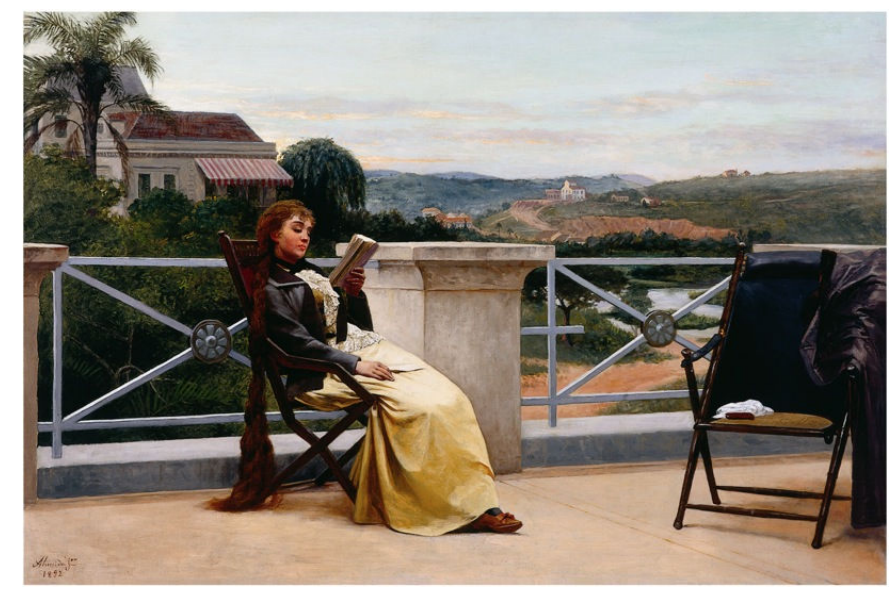

José Ferraz de Almeida Júnior (Itu, São Paulo, 1850 - Piracicaba, São Paulo, 1899)

Leitura, 1892

óleo sobre tela, $95 \times 141 \mathrm{~cm}$

Pinacoteca do Estado de São Paulo

Transferência do Museu Paulista, 1905

2 O Liceu de Artes e Ofícios de São Paulo foi fundado em 1873, inicialmente sob a denominação de Sociedade Propagadora de Instrução Popular que, como indica o nome, funcionava como uma escola de alfabetização para camadas da população menos favorecidas. Em 1882, a escola foi ampliada e reorganizada sob o nome de Liceu de Artes e Ofícios, alterando-se o programa curricular, buscando especialmente a formação de artífices. Quando o arquiteto Francisco de Paula Ramos de Azevedo (1851-1928) passa a fazer parte da diretoria da instituição, em 1894, há um grande crescimento e valoração dessa instituição. Ramos de Azevedo é ainda um dos criadores da Escola Politécnica de São Paulo e um dos maiores entusiasta da criação da Pinacoteca, inicialmente concebida como pequena galeria de pintura, ocupando salas do edifício do Liceu de Artes e Ofícios, a fim de educar artisticamente os alunos. Maiores detalhes sobre o Liceu podem ser consultados em: SEVERO, Ricardo. Licen de Artes e Ofícios de São Paulo. São Paulo: Liceu, 1934; BELLUZZO, Ana Maria de Moraes. Artesanato, arte e indústria. São Paulo: FAU-USP, 1988 (tese de doutorado); LICEU de Artes e Ofícios de São Paulo: missão excelência. São Paulo: Marca D’Água, 2000. 
Contudo, há mais de cinqüenta anos não era realizada ampla mostra do artista - a última ocorreu na própria Pinacoteca em 1950, em comemoração ao centenário de nascimento do pintor ituano e agregou obras da própria Pinacoteca e alguns exemplares de coleções particulares da própria cidade de São $\mathrm{Paulo}^{3}$, sem a participação de nenhuma obra de outra instituição, como o Museu Nacional de Belas Artes do Rio de Janeiro - o primeiro a possuir obras do pintor - ou ainda do Museu de Arte de São Paulo, que possui importantes obras do artista, normalmente armazenadas em reserva técnica. Como um dos poucos eventos comemorativos dos 150 anos de nascimento do artista foi realizada a exposição "Almeida Júnior: um artista revisitado", ainda na Pinacoteca do Estado, em $2000^{4}$.

A escolha por encerrar as comemorações do primeiro centenário desse Museu com a mostra do pintor relaciona-se em parte com o fato de a Pinacoteca possuir, até a data da exposição, 46 pinturas de Almeida Júnior ${ }^{5}$ - muitas das quais transferidas de outra instituição paulistana, o Museu Paulista $^{6}$, duas máscaras mortuárias, busto, caixa de tintas e pincéis e uma das paletas do artista ${ }^{7}$, além de contemplar, em diferentes momentos de sua existência, uma sala só para abrigar obras de sua autoria - como a que

3 A exposição contou com 35 obras da própria Pinacoteca e 15 obras pertencentes a coleções particulares.

4 Essa exposição contou com obras do próprio artista da Pinacoteca do Estado e do Museu Nacional de Belas Artes do Rio de Janeiro, além de releituras - reinterpretações visuais de obras já existentes de artistas contemporâneos sobre a produção do pintor ituano.

$5 \mathrm{O}$ colecionador Sérgio Pedro dos Anjos, em homenagem às comemorações do $1^{\circ}$ Centenário da Pinacoteca do Estado de São e da exposição "Almeida Júnior: um criador de imaginários" doou para a Pinacoteca do Estado a pintura $O$ estatuário, importante obra que participou da exposição organizada pelos amigos do artista em janeiro de 1900 e também do leilão realizado no mesmo ano.

6 O Museu Paulista foi o primeiro museu a existir na cidade de São Paulo e também o primeiro a exibir obras de arte. Inaugurado em 7 de setembro de 1895, em 1905, 26 de suas pinturas são transferidas para a Pinacoteca do Estado e dentre estas, quatro de Almeida Júnior. Entre 1938 e 1939, por determinação do então interventor federal no estado de São Paulo, Adhemar de Barros (1901-1969), o diretor do Museu Paulista, Affonso d'Escragnolle Taunay (1876-1958) é incumbido de agrupar o maior número de obras do pintor ituano para compor a Galeria Almeida Júnior, inaugurada oficialmente em agosto de 1939. Entre 1947 e 1948, outro grande conjunto de obras de Almeida Júnior foi transferido do Museu Paulista para a Pinacoteca do Estado (as de cunho artístico passam a fazer parte do acervo da Pinacoteca; as com características iconográficas ou históricas permaneceram no MP), em consonância com o momento histórico vivenciado na cidade, com a criação de novos museus como o Museu de Arte de São Paulo [1947] e o Museu de Arte Moderna [1948], numa tentativa de reorganização dos acervos. Dados obtidos em pesquisas nos setores de documentação da Pinacoteca do Estado e do Museu Paulista da Universidade de São Paulo, no segundo semestre de 2006.

7 Boa parte destes objetos também é proveniente do Museu Paulista. 
existe atualmente na exposição de longa duração que sempre apresenta parcela da produção considerada das mais importantes realizadas por Almeida Júnior, a relacionada com a temática interiorana, a mais conhecida e grande colaboradora para a formação do imaginário do caipira paulista. $\mathrm{O}$ que normalmente permanece nessa sala é a exibição de grande quantidade de obras comumente denominadas regionalistas, em que o contexto de organização corrobora para uma visão do artista reconhecido apenas por esta temática.

\section{A exposição: possíveis contribuições}

O que a exposição "Almeida Júnior: um criador de imaginários" procurou ressaltar foi a criação de outros imaginários pelo artista ituano para além do regionalista, do final do século XIX até o presente, e como ele pode ser considerado um homem de seu tempo, que descortina um horizonte voltado para o futuro e não para o passado, que está em sintonia com as mudanças ocorridas em seu período de atuação, a partir dos adventos da abolição da escravatura [1888], da Proclamação da República [1889], explicitando diferentes contendas e grupos de interesse. Aliado a isto, a idéia de um inventário dos objetos e atributos de determinados grupos, sejam os 'caipiras' ou os importantes líderes políticos do período; as possibilidades de um novo olhar sobre mulheres, crianças e velhos e a possível inserção, ainda que limitada no meio local, de um modo de viver moderno.

Como primeira etapa do trabalho coube a localização de grande conjunto de obras do artista - cuja primeira catalogação foi realizada pela curadora-geral da mostra, Prof. ${ }^{a}$ Dr. ${ }^{a}$ Maria Cecília França Lourenço, durante a pesquisa de mestrado realizada sobre a produção artística de Almeida Júnior, defendida como dissertação de mestrado na Escola de Comunicações e Artes da Universidade de São Paulo, em 1980. A partir do material existente, da revisão bibliográfica, da atualização da pesquisa em jornais do período, da localização de obras até então desaparecidas e de novas obras, foi possível rever pontos de vistas e estabelecer novas relações, não apenas com a pintura francesa realista do século XIX, que apresenta Gustave Courbet (1819-1877) e Jean-François Millet (1814-1875) como expoentes maiores, mas contatos e aproximações com obras de 
Édouard Manet (1832-1883), mas também com Jules Bastien-Lepage (1848$1884)^{8}$ e, especialmente, com o artista belga Alfred Stevens ${ }^{9}$ (1823-1906) e com o que, de maneira geral, pode-se chamar genericamente de escola holandesa de pintura.

\section{Organização formal da exposição}

A exposição foi dividida em cinco módulos, cujas cores utilizadas foram retiradas da própria paleta do artista existente na Pinacoteca, matizes que, ou estavam contidas no objeto, ou apareciam em quadros que se encontram nos referidos módulos; ainda trabalhou-se com a complementar de determinas pinturas. A seqüência de se partir de tonalidades quentes de amarelo, laranja, vermelho e vinho, para depois utilizar duas tonalidades mais frias de verde e de azul esverdeado, procurou chamar a atenção para as obras relacionadas com o viver moderno e para as cópias e releituras, como diferentes de uma narrativa crescente. Os módulos da exposição foram denominados: "Tempo humano" (amarelo), "Natureza e cotidiano" (vermelho), "Trabalhos em contraste" (vinho), "Espaço para a vida moderna" (azul) e "Artista como museu: cópias e releituras" (verde). A temática regionalista esteve presente em todos os módulos e muitas pinturas poderiam ser colocadas em diferentes segmentos, a partir da abordagem adotada.

Cabe salientar que, no hall de entrada da exposição, para o lugar em que foi colocado o texto de apresentação, foi realizada uma cópia de exibição da pintura de grandes dimensões Aurora, que foi a primeira encomenda importante do artista quando retornou para São Paulo de sua complementação formacional em Paris, realizada para a então residência de Dona Veridiana da Silva Prado, atual São Paulo Clube, numa rara

8 Assim como Almeida Júnior, Jules Batien-Lepage era proveniente de uma província, Damvillers; quando se transfere para Paris, igualmente é aluno de Cabanel na École des Beaux-Arts e participa do Salon Officiel des Artistes Français de 1870, 1872 e 1874. A maior parcela de sua produção versa sobre paisagens rurais.

${ }^{9}$ O pintor belga Alfred Stevens como Almeida Júnior vai para a Paris e estuda na École des Beaux-Arts. Narra situações capesinas, mas também cenas de gênero com belas figuras femininas - aproxima-se de Almeida Júnior na retração dessas mulheres mais liberadas. Chegam mesmo a ter trabalhos com o mesmo título, como Depois do baile. O pintor belga consegue, após o período de formação, instalar ateliê em Paris e hoje há obras suas em importantes museus do mundo como o Musée D’Orsay, o Hermitage e o Metropolitan americano, além de ser amigo de Édouard Manet. 
oportunidade de disponibilizar, mesmo que na forma de réplica, uma obra de difícil exibição.

\section{Módulos}

As obras do núcleo "Tempo humano" ressaltam bebês, meninos e meninas em diversas situações, e igualmente inúmeros rostos enrugados ante a implacável ação do tempo. Mais do que algo comum, nesses trabalhos o pintor parece se interrogar sobre o ser e o futuro. $O$ contraste entre crianças e velhos é bastante acentuado: se a infância revela a alegria de viver, o mesmo não aparece na velhice, muitas vezes cercada por sombras. Exceção são os retratos mais formais, em que são conservadas posturas próximas à dos retratos fotográficos, com expressões austeras que podem explicitar determinado papel na sociedade.

Em "Natureza e cotidiano", o olhar que faz ver adiante e se estende para diversos focos, em que o viver humano requer observação e análise. Este núcleo mostra como muitas vezes Almeida Júnior se debruçou como um cientista sobre a natureza, sua exuberância, generosidade e características singulares; ou ainda sobre a própria natureza humana, que igualmente ganha importantes estudos, de psicologia - buscando decifrar as diferenças e variações entre as sensações humanas e os mecanismos de percepção. Há, muitas vezes, uma delicada aproximação, em que o artista busca interpretar, de forma generosa, o interior espiritual de algumas figuras femininas.

"Trabalhos em contraste" é o módulo que mais explicita a temática regionalista. Curiosamente Almeida Júnior gravita do universo cosmopolita, reluzente e multifacetado para o mundo centrando no microcosmo interiorano, trazendo algo inovador para o período, como dito anteriormente. Como um estudioso do viver campesino, fixa e descreve instrumentos de trabalho, procedendo a um verdadeiro inventário. A mulher e o homem se encontram reunidos, transportando-nos para rotinas do interior, ainda hoje encontradas em diversas zonas rurais do Brasil. Tais telas revelam um pintor sensibilizado com as diversas possibilidades de trabalho, contrastando vida e labuta no campo com o viver e as profissões urbanas, ambos com a mesma dignidade. Nas pinturas que representam atividades agrárias, dominam longos tempos e simplicidade; nas que descrevem a vivência urbana, os símbolos de conhecimento e de poder das personalidades públicas. 
Em "O espaço para a vida moderna", o olhar investigativo do pintor possibilitou voltar-se para a intimidade da vida no ateliê, a representação dos novos papéis femininos, a utilização de novos equipamentos, e também para uma reflexão sobre a própria rotina do fazer artístico. A segunda metade do século XIX se encontra profundamente marcada pelo jargão da vida moderna, implicando de modo próprio o que se considerava deslumbrante na vivência urbana, tendo como uma das principais conseqüências a alteração do papel feminino na sociedade. A ampliação da participação da mulher no trabalho, a possível contribuição da máquina fotográfica na prática da pintura e as modificações dos valores burgueses se encontram em importante parcela das obras criadas por Almeida Júnior. O artista retrata diversas figuras femininas em suas obras, sempre revelando grande proximidade afetiva e adesão às conquistas desse grupo, seja no lazer ou no trabalho. A produção do pintor que tem como temática o ateliê explicita muitas vezes cumplicidade, sensualidade e liberdade, sendo então este espaço de trabalho transformado em um espaço da vida moderna, diferente do dominado por convenções sociais. Destacase ainda a fotografia, uma invenção do século XIX que, ao que tudo indica, esteve muito presente na prática profissional do pintor, seja para a realização de grande parcela dos retratos, muitos realizados com o auxílio desta técnica, seja para a confecção de estudos, espelhamentos de posições, reutilização de partes de corpos em novas composições em complexas combinações.

O último módulo é o denominado "Artista como museu: cópias e releituras" e foi montado na sala normalmente utilizada para exibir as pinturas de Almeida Júnior na exposição de longa duração. A realização de cópias de trabalhos de outros artistas foi prática muito valorizada durante o período de aprendizado dos artistas desde o Renascimento, particularmente valorizada pelas academias - como as que Almeida Júnior freqüentou. Aliase a este procedimento, a ausência total de museus de arte na cidade de São Paulo no final do século XIX e a dificuldade de complementação na formação profissional, o que ampliou o número desse tipo de obra. $\mathrm{O}$ próprio artista, em seu período de estudos, realizou cópias de pinturas de seus professores ou de artistas dos quais pôde conhecer trabalhos nos museus europeus que visitou. 


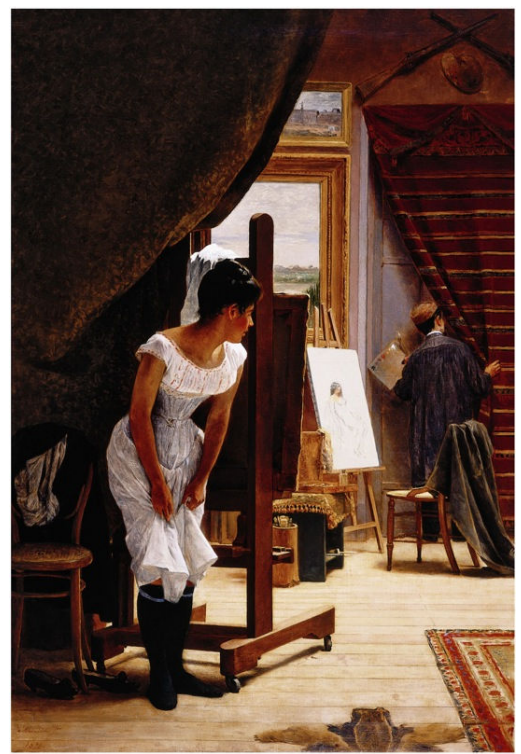

José Ferraz de Almeida Júnior (Itu, São Paulo, 1850 - Piracicaba, São Paulo, 1899) O importuno, 1898

óleo sobre tela, $145 \times 97 \mathrm{~cm}$

Pinacoteca do Estado de São Paulo - transferência do Museu Paulista, 1947

Graças à grande aceitação das pinturas de Almeida Júnior por diferentes segmentos da sociedade, cópias de obras do pintor foram realizadas já por seus contemporâneos, servindo de exemplo, ao mesmo tempo em que também foi adaptado o conteúdo inicialmente utilizado pelo artista para outras cenas da vida rural.

Em relação às releituras, a obra de Almeida Júnior serviu diversas vezes de inspiração para outros profissionais das artes. As releituras fazem parte do imaginário que se consolidou da produção do artista e procuram, muitas vezes, aprofundar a compreensão do significado de sua pintura, por meio da retomada de alguns símbolos que podem se desdobrar em diversos significados.

Aspecto importante que a mostra procurou ressaltar foi a realização por Almeida Júnior obras semelhantes em diferentes tamanhos e com pequenas diferenças. Em alguns pontos, obras com tais características eram postas lado a lado; em outros, isoladas, chamando a atenção do olhar para essa prática comum do século XIX. Como Almeida Júnior sempre viveu do próprio ofício, a questão da encomenda é primordial na sua 
produção e ele deve ter realizado muitas pinturas semelhantes a pedido dos clientes; corrobora para as diferentes versões o fato de o artista raramente executar desenhos preparatórios, preferindo normalmente o embate direto com a tela. Essa escolha a princípio gerou um certo estranhamento mas, por outro lado, possibilitou explicitar importantes mecanismos de criação do trabalho do artista.

\section{Outros olhares sobre o século XIX brasileiro}

Para o evento foi realizado amplo levantamento fotográfico - utilizadas para o material impresso -, contemplando todas as obras que participaram da exposição e também outras de instituições como o Museu Paulista da Universidade de São Paulo, a Faculdade de Direito da Universidade de São Paulo e a Igreja Nossa Senhora Candelária de Itu, entre outras; pesquisa sobre a procedência das obras da Pinacoteca do Estado de São Paulo; realização de catálogo com textos e cronologia inéditos realizados pela curadoria, além de textos de outros pesquisadores; revista, espécie de versão reduzida do catálogo; folder preparado pelo setor educativo da instituição e uma cronologia ilustrada na parte externa da exposição. Foram organizados ainda uma série de eventos abertos ao público, como mesa-redonda e batepapos com a curadoria, com o intuito de ampliar o debate sobre o artista e a arte brasileira do século XIX, numa rara oportunidade de aprofundamento de pesquisa e reflexão dentro de uma instituição museal.

A exposição realizada em nenhum momento pretendeu esgotar a análise sobre a produção pictórica de Almeida Júnior; ao contrário, ela buscou levantar questões que poderão ser retomadas, visando a ampliação de análises e estudos sobre a arte brasileira do século XIX, no qual a pintura é um indício e reflexo de um aspecto mais amplo, além de trazer a possibilidade de aproximar o fruidor do contato direto com as obras.

Ainda que toda a produção artística do século XIX brasileiro tenha sido (e em grandes segmentos ainda seja) considerada por muito como subarte, acredito ser importante o estudo do período, tão obliterado pelos modernistas e contemporâneos, entendida em bloco, sem a observação das peculiaridades e diferenças. A obra de Almeida Júnior traz em seu bojo uma série de questões que já estão latentes no século XIX, mas que só tomarão forma completa no século XX.

Uma questão que igualmente me parece muito importante é que o sempre visível, não é mais olhado em particularidade, ou nem é mais notado (como os percursos que realizamos todos os dias) ou nem vemos 
mais, o que pode acontecer com muitas obras, quando reproduzidas à exaustão, banalizando a imagem a ponto de não olharmos mais para elas, só percebendo sua falta quando colocadas em outro contexto.

\section{Bibliografia}

ALMEIDA Júnior: homenagem do governo do Estado de São Paulo no $1^{\circ}$ centenário do seu nascimento. São Paulo: Prefeitura, 1950. (catálogo de exposição).

ALMEIDA Júnior: um criador de imaginários. São Paulo: PESP, 2007.

ARAÚJO, Emanoel; AMARAL, Aracy \& LOURENÇO, Maria Cecília França. José Ferraz de Almeida Júnior (1850-1899): um artista revisitado. São Paulo: PESP, 2000.

AULER, Guilherme. Os bolsistas do Imperador. Petrópolis: Tribuna de Petrópolis, 1956

BELLUZZO, Ana Maria de Moraes. Artesanato, arte e indústria. São Paulo: FAU-USP, 1988 (tese de doutorado)

EXPOSIÇÃO Almeida Júnior: homenagem da comissão de amigos, em 11 jan. 1900. São Paulo: Tipografia Andrade Melo, 1900.

LICEU de Artes e Ofícios de São Paulo: missão excelência. São Paulo: Marca D’Água, 2000.

LOURENÇO, Maria Cecília França. Revendo Almeida Júnior. São Paulo: ECA-USP, 1980. (dissertação de mestrado)

MARCONDES, Marcos (org.). Almeida Júnior: vida e obra. São Paulo: Art Editorial, 1979. (org.). Almeida Júnior: vida e obra. São Paulo: Art Editorial; Círculo do Livro, 1985.

NASCIMENTO, Ana Paula \& MAU, Maia. Cronologia em primeira mão. In: ALMEIDA Júnior: um criador de imaginários. São Paulo: Pinacoteca do Estado, 2007, p. 3 -29. (catálogo de exposição)

NAVES, Rodrigo. O sol no meio do caminho. Novos estudos Cebrap. São Paulo: 73: 135-148.

REWALD, John. História do impressionismo. São Paulo: Martins Fontes, 1991, p. 458-462

SCHWARCZ, Lilia Moritz. As barbas do Imperador: D. Pedro II, um monarca tropical. São Paulo: Cia. das Letras, 1998.

SEVERO, Ricardo. Liceu de Artes e Ofícios de São Paulo. São Paulo: Liceu, 1934.

Ana Paula Nascimento: arquiteta formada pela Faculdade de Arquitetura da Universidade de São Paulo. Atualmente, pesquisadora do setor de pesquisa em crítica e história da arte da Pinacoteca do Estado de São Paulo. Doutoranda da FAU/USP, cujo trabalho em andamento versa sobre a cidade de São Paulo da virada do século XIX para o XX. Mestrado realizado na mesma instituição, com pesquisa sobre a formação do Museu de Arte Moderna de São Paulo e as relações culturais da cidade na década de 1940. 